\title{
Feasibility Study for the Evaluation of Chicken Meat Storage Time Using Surface Acoustic Wave Sensor
}

\author{
Geonwoo Kim ${ }^{1} \cdot$ Byoung-Kwan $\mathrm{Cho}^{2} \cdot$ Sang Hyub Oh ${ }^{3} \cdot \mathrm{Ki}^{-B o k ~ K i m}{ }^{4}$
}

Received: 2 July 2020 / Revised: 14 September 2020 / Accepted: 15 September 2020 / Published online: 6 October 2020

(C) The Author(s) 2020

\begin{abstract}
Purpose The objectives of this study are to provide the detailed information of designing, fabrication process, and performance test results of a surface acoustic wave (SAW) sensor for evaluating chicken meat storage time (up to 15 days).

Methods The aldehyde gas generated from chicken meat was selected as the reactive material, and Love wave was used among various SAWs due to its high sensitivity of the aldehyde gas particles. The SAW sensor was fabricated on the surface of $\mathrm{LiNbO}_{3}$ piezoelectric wafer with a cross-linked polydimethylsiloxane (PDMS)-sensitive layer using standard photolithographic techniques. To analyze the fabricated SAW sensor characteristics, the $S_{21}$ parameters and base line noise were acquired by a vector network analyzer. Before measuring chicken meat gas samples, a reference gas (a mixture of 25, 50, 75, and 100 ppm acetaldehyde (a functional group with the structure $-\mathrm{CHO}, \mathrm{CH}_{3} \mathrm{CHO}$ ) and nitrogen $\left(\mathrm{N}_{2}\right)$ gas) was measured to verify the reactive performance of the SAW sensor. Among the VOCs from chicken meat gas, $\mathrm{CH}_{3} \mathrm{CHO}$ was selected as an intrinsic biomarker due to its harmful effects on the human body. Then, aldehyde gas from chicken meat samples was measured and the phase changes of the response signals with increasing the chicken meat storage time were obtained by the SAW sensor.

Results About $-4 \mathrm{~dB}$ insertion loss occurred due to the PDMS coating and the high electromechanical coupling factor of used substrate. The phases of the response signals decreased linearly with increase of both the reference gas concentration and the storage time of the chicken meat samples. The determination coefficients of the reference gas and the storage time were over 0.9. The results show that the developed SAW sensor can provide valuable information about evaluating the chicken meat storage time.

Conclusion The newly developed SAW sensor clearly demonstrates that chicken meat storage could be evaluated by detecting aldehyde gas. This opens a promising research avenue to explore.
\end{abstract}

Keywords Aldehydes $\cdot$ Chicken meat $\cdot$ Cross-linked polydimethylsiloxane $\cdot$ Love wave $\cdot$ Surface acoustic wave sensor

\section{Introduction}

Chicken meat is one of the most commonly consumed meats around the world, and it should be kept cold during distribution to retail stores to prevent the growth of bacteria and to

Geonwoo Kim

gumppang01@ naver.com

Byoung-Kwan Cho

chobk@cnu.ac.kr

Sang Hyub Oh

shoh@kriss.re.kr

Ki-Bok Kim

kimkibok@kriss.re.kr increase its shelf life (Igene et al. 1979; Silva and Glória 2002; Soyer et al. 2010). The quality of chicken meat varies with several factors during the slaughtering process, storage, and distribution. Therefore, technology for sensing the quality of chicken meat has become important in various food industries

1 Environmental Microbial and Food Safety Laboratory, Agricultural Research Service, U.S. Department of Agriculture, Powder Mill Rd. Bldg. 303, BARC-East, Beltsville, MD 20705, USA

2 Department of Biosystems Machinery Engineering, Chungnam National University, Daejeon 305-764, Republic of Korea

3 Center for Gas Analysis, Korea Research Institute of Standards and Science, Daejeon 34113, Republic of Korea

4 Center for Safety Measurement, Korea Research Institute of Standards and Science, 267 Gajeong-ro, Yuseong-gu, Daejeon 34113, Republic of Korea 
(Le Bihan-Duval et al. 1999; Lopez-Ferrer et al. 2001; Patsias et al. 2008). The deterioration of the freshness of meats usually begins with the breakdown of protein and fat, which are caused by enzymes secreted by microorganisms. Thus, a variety of volatile organic compounds (VOCs) are released by the microorganisms that live in meat and they can typically be analyzed using solid-phase microextraction (SPME). SPME is an effective sample preparation technique that involves several operations such as sample collection, extraction, analyte enrichment, and isolation from sample matrices and has been used to extract analytes (including both volatile and nonvolatile) from different kinds of gaseous, liquid, and solid phase. Microorganisms such as Salmonella enteritidis, Escherichia coli, Klebsiella pneumonia, and Enterobacter cloacae are the primary causes of the VOCs that can be found in pork, goose, and duck meats, as well as in chicken meats (Arnold and Senter 1998; Du et al. 2000; Eilamo et al. 1998; Soncin et al. 2007). In addition, because an aldehyde is a compound including a functional group with the structure $\mathrm{CHO}$, acetaldehyde can be also classified as aldehyde gas. Among the VOCs, acetaldehyde, an organic chemical compound with the formula $\mathrm{CH}_{3} \mathrm{CHO}$ in aldehyde group and a result of ethanol metabolism, is one of the most important factors considered in sophisticated packaging systems regarding contamination from packing. Numerous studies on the correlation between aldehydes in the human body and specific illnesses have recently been conducted (Bicanic et al. 2003; Fromme et al. 2008; Nanto et al. 2000; You et al. 2009). Thus, it is classified as a carcinogen and its maximum permitted concentration is 25 ppm per $8 \mathrm{~h}$, as defined by the American Conference of Governmental Industrial Hygienists (ACGIH) (Giberti et al. 2012; Mitsubayashi et al. 2005). Its inhalation can cause serious health problems related to the central nervous system such as headache, paralysis, respiratory disorders, and a comatose state (Jun et al. 2011; Yamashita et al. 2010).

Therefore, in this study, $\mathrm{CH}_{3} \mathrm{CHO}$ was selected as the reference gas for evaluating aldehydes from chicken meat in relation to storage time. Recently, a number of sensing methods have been developed (such as spectroscopy, gas chromatography, chemo-resistivity, chemo-capacitance, field effect gas sensors, amperometry electrochemical cells, and electronic nose systems) that are useful for detecting aldehydes in air and liquid phases (Calestani et al. 2011; Giberti et al. 2012; Jun et al. 2011; Mitsubayashi et al. 2005; Yamashita et al. 2010). Among these methods, electronic nose systems have been widely studied for evaluating the freshness and a quality of food by analyzing VOC components (Fitzgerald et al. 2017; Loutfi et al. 2015). They can be used to assess the changes in quality and thus, how long meats have been in cold storage (according to the type of food) (Boothe and Arnold 2002; Di Natale et al. 1997; Olafsdottir et al. 2005). The application of electric nose techniques, with respect to the freshness levels of fish species and meats, accounts for a large area of VOC analysis. However, to the best of our knowledge, studies on the rapid evaluation of aldehyde gas from chicken meat have rarely been conducted using a non-destructive testing method (Loutfi et al. 2015). For the rapid and precise detection of VOCs, surface acoustic wave (SAW) devices have drawn a substantial attention for biosensing applications. Their advantages include simple sensing structure, cost-effective capabilities, relatively small size, fabrication reproducibility, and fast output. These qualities make them attractive choices for various VOCs and liquid sensors (Biswas et al. 2004; Leonte et al. 2006; Liu et al. 2011; Shen and Liou 2008; Wen et al. 2007). Accordingly, we selected the SAW sensor for the evaluation of aldehyde gas from chicken meat. For SAW gas sensing, its surface is coated with a chemically active membrane (sensitive layer), which can absorb specific gas molecules. The sensitive layer responds to mass changes on its surface with a frequency shift and can be used for gas-phase sensing applications (Horrillo et al. 2004; Pan et al. 2014). Therefore, a chemically selective layer should be used to collect and concentrate target molecules on its surface. To accomplish this, cross-linked polydimethylsiloxane (PDMS)-based sensing techniques have been selected because of it being inexpensive, flexible, and nontoxic, and exhibit a swelling effect upon absorbing volatile aldehyde molecules (Horrillo et al. 2004; Lin et al. 2008; Ning et al. 2016; Weng et al. 2009). In addition, the PDMS-based sensitive layer can easily be achieved using a spin-coating method on a SAW inter-digital transducer (IDT) (Almenar et al. 2007; Joo et al. 2007; Lee et al. 2013; Weng et al. 2009; Wyszynski et al. 2010).

Among various SAWs, the Love wave was selected due to its excellent ability for detection of specific molecular interactions between its sensitive layer and piezoelectric substrate. Based on the above techniques, the SAW sensor was designed to respond to changes in the phase when it is exposed to aldehyde gas. Before measuring the aldehyde, gas generated from chicken meat samples, a reference material (a mixture of $\mathrm{CH}_{3} \mathrm{CHO}$ and $\mathrm{N}_{2}$ gas) was measured using the SAW sensor for verifying its reacting performance and aldehyde gas from actual chicken meat was evaluated.

\section{Materials and Methods}

\section{Analysis of Gas Components from Chicken Meat in Relation to Its Time of Storage}

Fresh chicken meat from a slaughterhouse was purchased and sliced. Samples $(150 \mathrm{~g})$ of the chicken meat were put into glass bottles that were sealed with a cap. These were then stored at $4{ }^{\circ} \mathrm{C}$ for intervals from 1 to 15 days. Differences in the gaseous components of the chicken meat samples stored 
for different intervals were analyzed using the SPME method. With the gas chromatography-mass spectrometry (GC-MS Saturn 2000, Varian Inc., CA, USA) technology associated with this method, it is possible to detect and identify volatile compounds. The analysis involved the use of an HP-5 capillary column (Cross-linked 5\% PHME siloxane, HewlettPackard Co., CA, USA). The temperatures of the column and of the injector were set to $260{ }^{\circ} \mathrm{C}$, and helium was used as the carrier gas. The thickness of the fiber that collected the gas components was $50 \mu \mathrm{m}$, and the fiber was coated with divinylbenzene (DVB)/carboxin (CAR)/PDMS. Chicken meat samples $(5 \mathrm{~g})$ were each put into a vial and sealed with a septum. After incubating a vial with the chicken meat sample at $37^{\circ} \mathrm{C}$ for 20 minutes, the gases from the headspace were allowed to adhere to the fiber for 3 minutes, after which their spectra were analyzed by software included with the GC-MS device.

\section{SAW Sensor Design and Fabrication}

The SAW sensor was designed to detect aldehyde gas in order to evaluate the time chicken meat had been stored. The SAW sensor consisted of input and output IDTs, a sensitive layer, acoustic absorbers to reduce triple transit echo, and a piezoelectric substrate. Fig. 1 shows a conceptual diagram of the structure of the SAW sensor.

In Fig. 1, the acoustic waves are generated by supplying a voltage to the input IDTs on the piezoelectric substrate and they travel along both $\mathrm{x}$-directions. When propagating both $\mathrm{x}$ directions on the surface of the piezoelectric substrate, one passes under the sensitive layer and the other reaches to the acoustic absorber. The output IDT receives and converts the acoustic waves into electrical signal (voltage), and the acoustic absorber attenuates the unnecessary mechanical energy.

The IDTs consist of a pair of electrodes and many of repeated parallel fingers are connected to each other. When excitation voltage is applied to produce a potential acoustic energy, the piezoelectric substrate is deformed and changes the electrical energy into the acoustic energy. The nature of the acoustic wave depends on the sound speed of the used piezoelectric substrate $(v=f \times \lambda, v, f$, and $\lambda$ are sound velocity, operating frequency, and wavelength of piezoelectric substrate). The width between the fingers is typically calculated to be a quarter wavelength of the sound speed of the piezoelectric substrate $\left(\mathrm{LiNbO}_{3}\right.$ wafer, about $\left.4000 \mathrm{~m} / \mathrm{s}\right)$ (Lee et al. 2011, 2012).

In this study, single IDT pattern design was used due to its advantages of simple structure and high sensitivity. Although double IDT design can provide effective resolution and decrease signal distortion characteristics generated between the IDT electrodes, single IDT design was used, because high sensitivity is one of the most important factors for biosensing application. In addition, more precise control for fabricating double IDT pattern requires high cost as well as increases error rate for the entire SAW sensor system. The operating frequency of the newly fabricated SAW sensor, the finger width of the IDT, the number of finger pairs, the length of each finger, and the distance between the IDTs were $160 \mathrm{MHz}, 6 \mu \mathrm{m}, 25,1.2 \mathrm{~mm}$, and $2 \mathrm{~mm}$, respectively.

SAW is produced by piezoelectric effect which converts the mechanical energy into electrical energy, and vice versa. To select an appropriate piezoelectric material for SAW application, electromechanical coupling coefficient $\left(k_{2}\right)$, temperature coefficient of delay (TCD), and temperature coefficient of frequency (TCF) should be considered (Gizeli et al. 2003; Lee et al. 2012), because chicken meat is transported under cold packaging and gas sensing requires high sensitivity. In general, Quartz, $\mathrm{LiNbO}_{3}$, and $\mathrm{LiTaO}_{3}$ have been widely used for the piezoelectric substrate for SAW sensor applications. Among them, $128^{\circ}$ cut $\mathrm{YX}-\mathrm{LiNbO}_{3}$ wafer was selected because it satisfied the above conditions.
Fig. 1 Conceptual diagram of the surface acoustic wave sensor

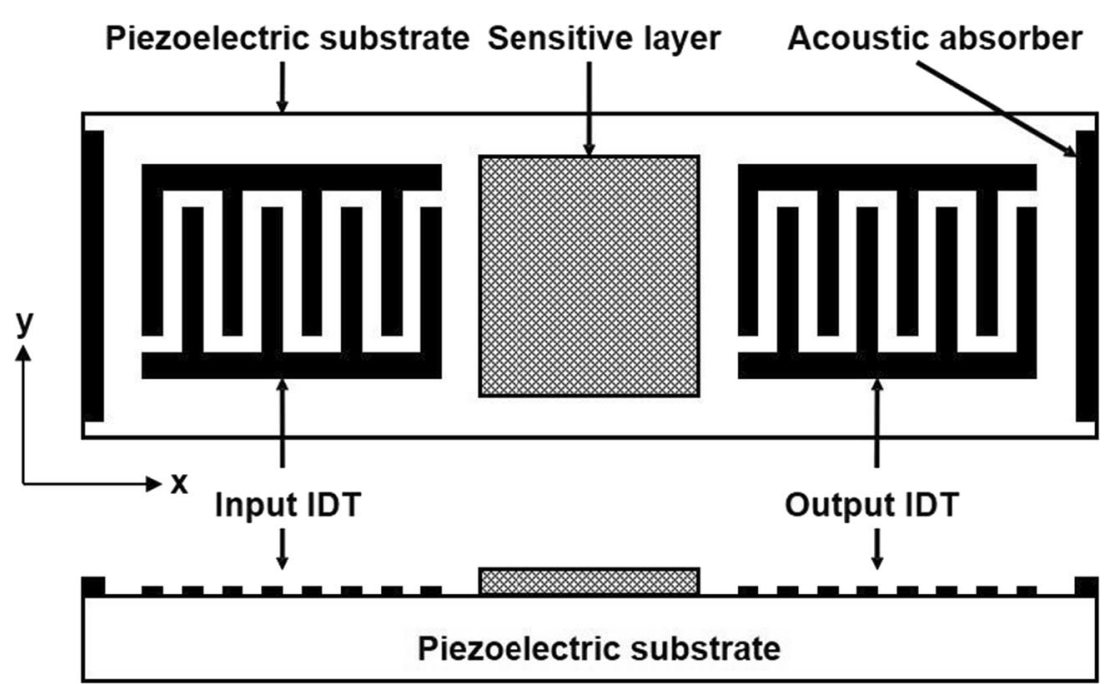


The area of the sensing layer was $2.4(=2 \times 1.2) \mathrm{mm}^{2}$. For the IDT patterns, 1000 - $\AA$-thick Au and 200-Å-thick Ti layers were deposited onto each piezoelectric substrate using a sputtering method. The mixture of $25 \mu \mathrm{m}$ tungsten powder (W006021, Good Fellow Inc., LDN, UK) and epoxy resin (Araldite GY509, Huntsman Co., TX, USA) was used for the acoustic absorber because of high acoustic impedance of tungsten (about $100 \mathrm{~kg} / \mathrm{m}^{2} \mathrm{~s}$ ). Moreover, the tungsten powder scatters the acoustic waves as well as attenuates ultrasonic energy.

The substance selected for use in the sensitive layer for aldehyde detection was PDMS. It was selected because of its high sensitivity to aldehyde gas (Firpo et al. 2015; Joo et al. 2007; Lachenmeier et al. 2006; Ning et al. 2016; Staginus et al. 2013; Torino et al. 2017). Love waves propagate near the surface of a piezoelectric substrate supporting shear horizontal waves. Because of this perturbation effect between the sensitive layer and piezoelectric substrate, the acoustic energy of the Love wave can be concentrated in the thin sensitive layer deposited on the surface of a $\mathrm{LiNbO}_{3}$ wafer. The Love wave SAW sensor can respond to the aldehyde gas particles that are adsorbed to the sensitive layer (Jakoby and Vellekoop 1998; Saha et al. 2003). Therefore, among various options for SAWs, the Love wave was selected for use in aldehyde sensing. Theoretically, considering the change in displacements with increase of the thickness of the sensitive layer, high mass sensitivity can be obtained in layer-guided acoustic wave systems. When the first mode of a Love wave begins, and the thickness of the sensitive layer is increased from zero, the displacement pattern takes the form of a plane wave in the substrate. Then, the sensitive layer assumes a quarterwavelength pattern. Additional increases in the thickness of the sensitive layer will further restrict its displacement, but this is not consistent with higher sensitivity (Gizeli et al. 2003; McHale et al. 2002). Hence, the optimal thickness of the PDMS layer was calculated by considering the quarter wavelength of the PDMS. For the best results, the most appropriate thickness of the PDMS-sensitive layer $(1.69 \mu \mathrm{m})$ for maximum sensitivity was calculated based on preliminary studies (Lee et al. 2011, 2012; McHale et al. 2002). The measured sound propagation speed of a PDMS specimen was about $1068 \mathrm{~m} / \mathrm{s}$. The sensor was mounted on a Teflon-jig with a semi-precision coaxial RF connector to prevent electrical noise. Fig. 2 shows the fabrication process of the SAW sensor with the PDMS-sensitive layer added using a spin-coating method.

\section{Experimental Set for SAW Sensor}

In this study, the experiments of the SAW sensor were performed by two stages: the reference gas and chicken meat gas sensing. The reference gas sensing was performed to verify the sensing ability of detecting $\mathrm{CH}_{3} \mathrm{CHO}$ gas and a gas mixture of $\mathrm{CH}_{3} \mathrm{CHO}$ (purity $99.99 \%$ ) and $\mathrm{N}_{2}(99.99 \%)$ was used as the reference gas and the concentration levels of the mixed gases were $25,50,75$, and $100 \mathrm{ppm}$, respectively. Two experiments were performed in a room with controlled humidity and temperature $\left(25^{\circ} \mathrm{C}\right)$ by the experimental set shown in Fig. 3. The following figure shows the experimental setup for the measurement of the reference aldehyde gas.

The experimental setup consisted of a mass flow controller (MFC 5850E, Brooks Inc., PA, USA) to control the flow rate of the mixed gases, a flow and pressure controller (GMC1220, ATOVAC Co. Ltd., Yongin-si, Rep. Korea) to let the gases be mixed at different concentrations, and a vector network analyzer (HP 8520D, Agilent Technologies Inc., CA, USA) connected to a laptop computer via a USB/GPIB interface. While mixing $\mathrm{N}_{2}$ gas with $\mathrm{CH}_{3} \mathrm{CHO}$ gas, the vector network analyzer activates the SAW sensor and the mixed gas is provided into the SAW sensor and the $\mathrm{S}_{21}$ parameters of the SAW sensor were acquired. S-parameters describe the relationship of input-output between ports in an electrical system and $\mathrm{S}_{21}$ parameter represents the power transferred from port 1 to port 2. The network analyzer generates broadband frequency. Then, the SAW sensor receives and excites its mechanical vibration. Before measuring the mixed gas, the $\mathrm{N}_{2}$ gas was inserted into the SAW sensor for $300 \mathrm{~s}$ for the stabilization of the SAW sensor. The same stabilization process was performed when measuring each different concentration level, and the mixed gas sensing was also conducted for $300 \mathrm{~s}$. After sensing the mixed and stabilization gases, the used gases were ventilated through the hood system. Then, the operating frequency and phase changes of the SAW sensor were measured and analyzed. For the aldehyde gas sensing experiment of chicken meat, the gas data based on the phase changes of the SAW sensor in relation to the number of days with the samples had been stored were measured using the same experimental setup as in Fig. 3 without the gas mixing stage. The storage interval over which the chicken meat samples had been stored was evaluated by detecting aldehyde gas.

Among the components of the SAW sensor, the IDT pattern and sensitive layer are the most important parts for determining the repeatability and reproducibility of the sensor system because operating frequency and phase of the SAW sensor are changed according to the mass of target molecule $\left(\mathrm{CH}_{3} \mathrm{CHO}\right)$ on the sensitive layer and IDT produces the acoustic waves affected by the sensitive layer. Therefore, in this study, to protect the sensing part from external inflow gas, a small acrylic chamber (volume $50 \mathrm{~mm}^{3}$ ) was constructed around the sensing area and sealed using epoxy resin (Araldite GY509, Huntsman Co., TX, USA) to prevent leakage of the chicken gases. The gases were collected by syringe from the glass sample bottles and injected onto the PDMSsensitive layer through a 1.6-mm Teflon tube connected to the small chamber of the SAW sensor. The changes in the phase of the SAW sensor were measured according to changes in the 
Fig. 2 Fabrication process of the newly developed SAW sensor

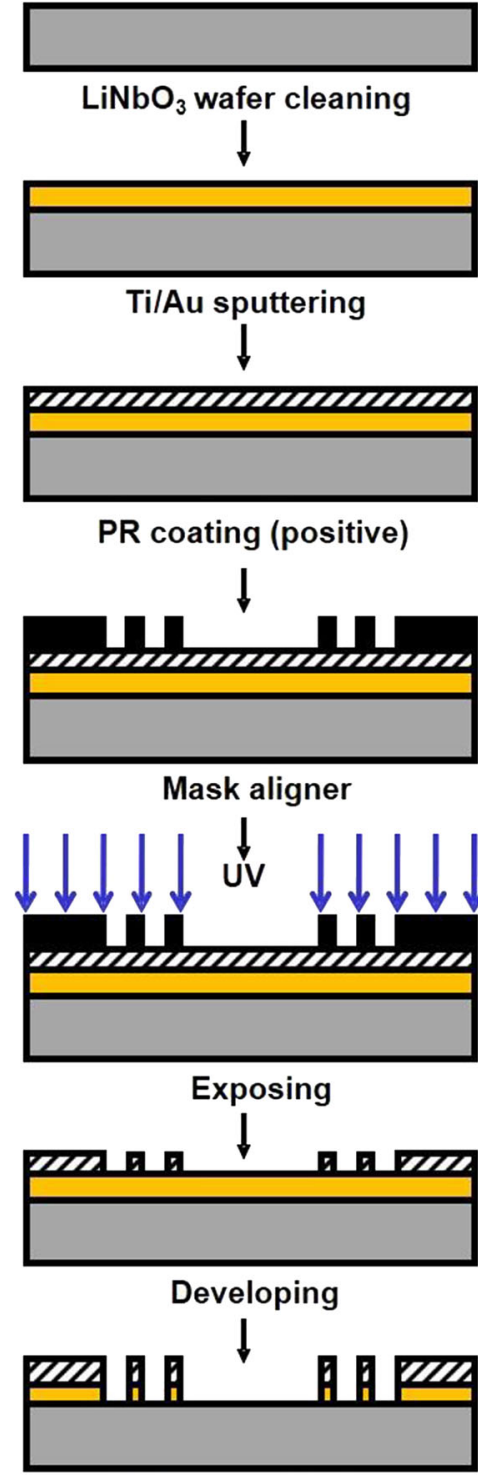

Ti/Au dry etching

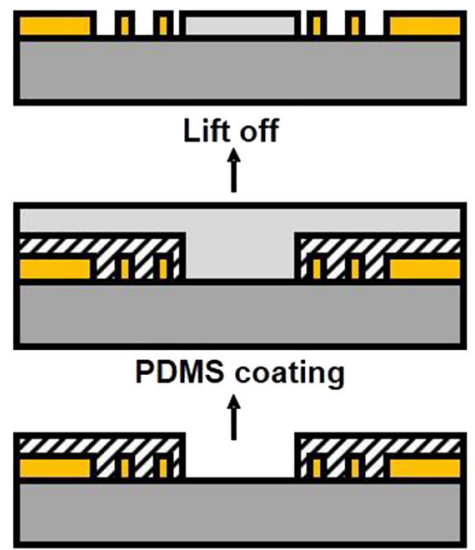

Developing

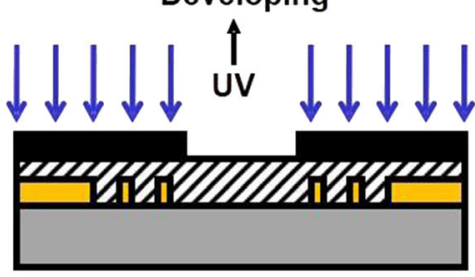

Exposing

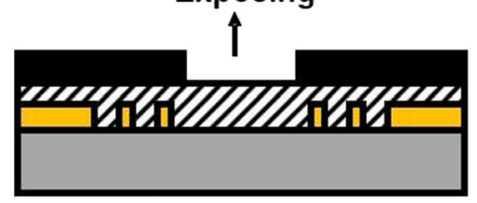

Mask aligner

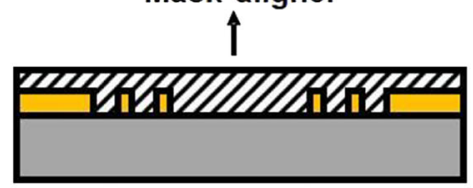

PR coating (positive)

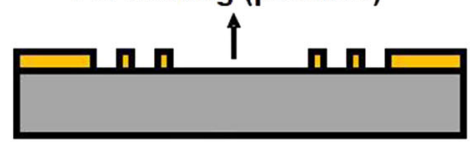

PR strip storage days. The phases of the SAW sensor are described in Eq. 1 (Ballantine Jr et al. 1996).

$\frac{\Delta \phi}{\phi} \propto \frac{\Delta f}{f_{0}}=f(\Delta m)$

where $\phi, \Delta \phi, f_{0}, \Delta f$, and $\Delta m$ are the phase in radians, the phase change, the resonant frequency in $\mathrm{Hz}$, the frequency change, and the mass loading of the target material, respectively.

\section{Results and Discussion}

\section{Chicken Meat Gas Analysis}

The concentrations of the gas components in the chicken meat samples (e.g., alcohols, ketones, esters, hydrocarbons, aldehydes, sulfur compounds) varied according to the storage period, and the results are shown in Fig. 4. In general, the amounts of these gases increased with increase in the storage interval. In particular, the amounts of alcohols and aldehydes increased rapidly after 5 days and the amounts of esters, ketones, and sulfur compounds increased rapidly after 10 days. The target gas component selected for evaluating the freshness of chicken meat was aldehyde. This is a group of organic compounds produced after microbial consumption of alcohol, which shows a rapid increase after 5 days of storage.

In Fig. 4, the concentrations of sulfur compounds and hydrocarbons account for about $90 \%$ among VOCs. However, these gases could not be the major indicators for evaluating chicken meat gas because sulfur is a mineral that the body uses for various functions, including making and repairing DNA. Lots of foods and beverages contain sulfur. Especially, 


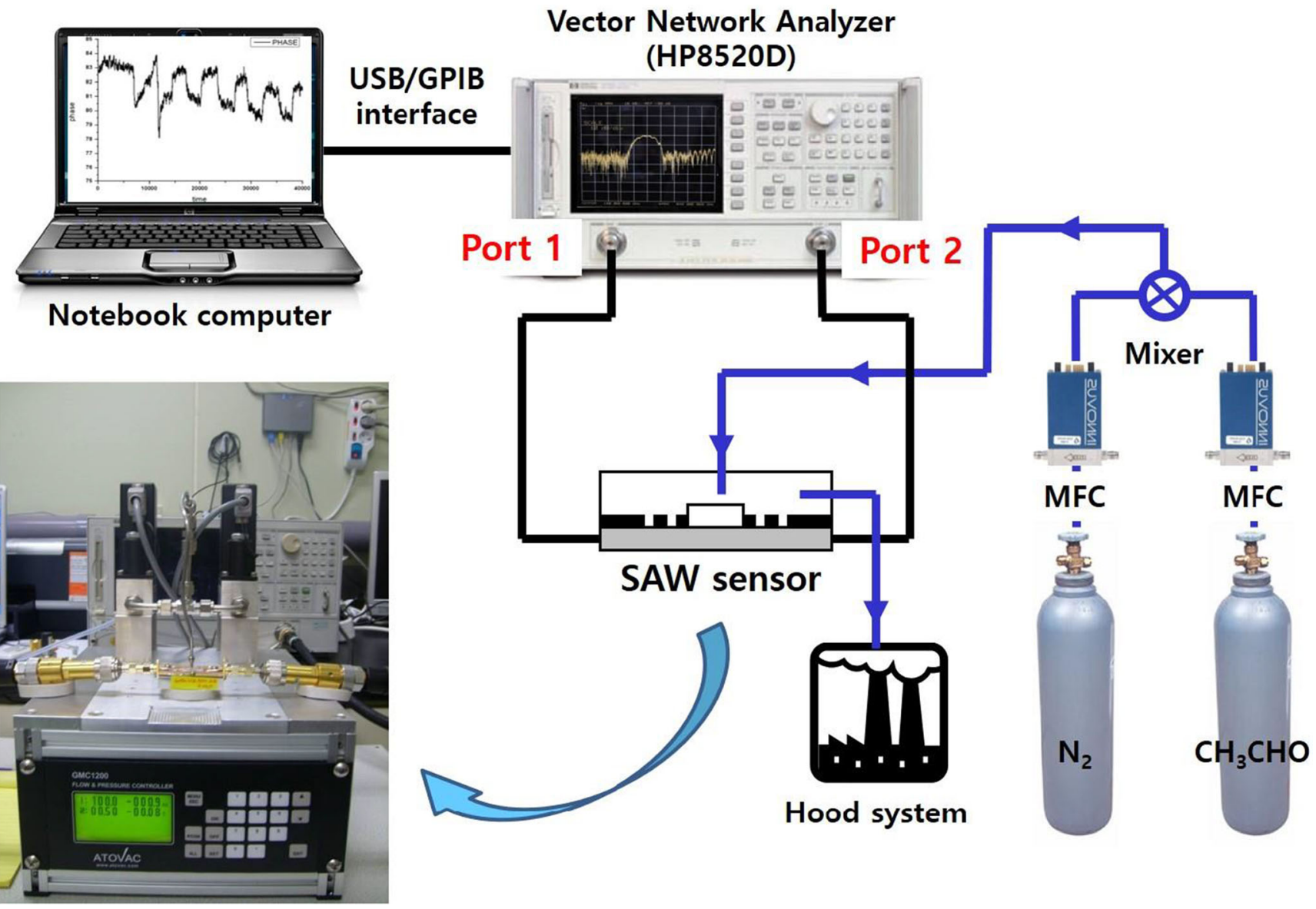

Fig. 3 Experimental setup for detecting the $\mathrm{CH}_{3} \mathrm{CHO}$ reference gas

fermented food such as beer, cheese, and wine also produces volatile sulfur compounds (Landaud et al. 2008). Food is composed of many kinds of hydrocarbon. Esters occur naturally in fruits and can enhance their flavors and the major ingredient in alcoholic beverages. Ketones are water-soluble molecules that are produced by the liver and have been considered as a carrier of energy to peripheral tissues for exercise (Newman and Verdin 2014). Therefore, we selected aldehydes because of their harmful effects (Giberti et al. 2012; Mitsubayashi et al. 2005).

\section{$\mathrm{S}_{21}$ Parameter Response and Base Line Noise}

As mentioned above, although the amount of the aldehyde gas was the third lowest in terms of dominance in the headspace in Fig. 4, it was selected due to the extremely harmful effects on the human central nervous system (e.g., allergenic hypersensitivity diseases, respiratory allergies, and idiosyncratic drug toxicity). Before sensing aldehyde gas, the frequency responses of the newly developed SAW sensor were measured using a vector network analyzer, by which its $S_{21}$ parameters were acquired in air at room temperature. To analyze the effects of the PDMS coating, we compared the sensitivity before and after PDMS coating, and measured the insertion losses. Fig. 5 shows the results of the comparison.

In Fig. 5a, the red line and black dashes are the frequency responses of before and after PDMS coating, respectively. An insertion loss of about $-4 \mathrm{~dB}$ and a center frequency shift of $0.34 \mathrm{MHz}$ were found due to the mass loading effect of the PDMS layer. If the insertion loss is relatively large in the results without and with the PDMS layer, the sensitivity of the SAW sensor may be low, but in this study, the insertion loss of $-4 \mathrm{~dB}$ is relatively small because the performance of the piezoelectric material was determined using the electromechanical coupling factor $\left(k_{\mathrm{p}}\right)$, the efficiency of converting mechanical energy into electrical signals. The $\mathrm{LiNbO}_{3}$ wafer possessed good stability of its electromechanical properties in the temperature range between 0 and $100{ }^{\circ} \mathrm{C}$ (Chen et al. 2019).

In Fig. 5b, after the PDMS coating, the phase was measured to analyze the baseline noise for about $1000 \mathrm{~s}$. Baseline noise is the short time variation of the baseline after chemical response caused by electric signal fluctuations, chemical reaction, temperature fluctuations, and other factors. Usually, the stability of the SAW sensor signal can be achieved by measuring the baseline noise of the sensor system and the effective 


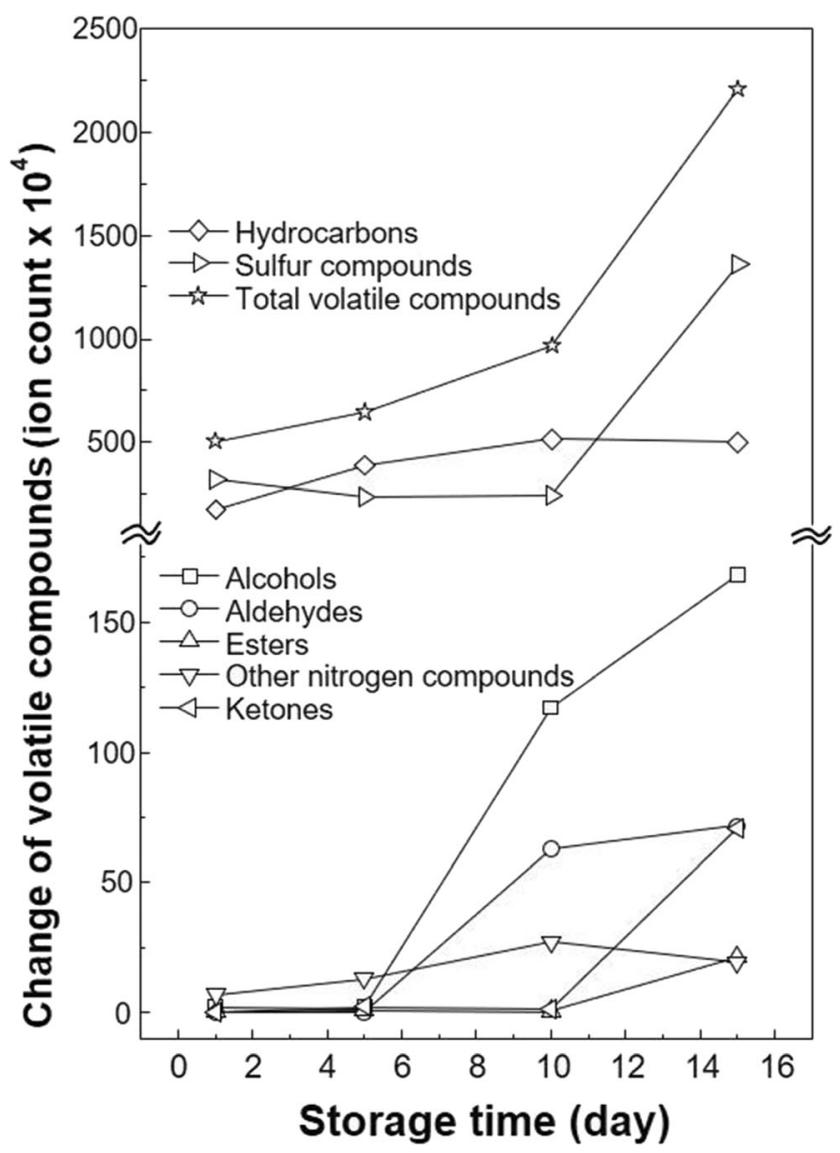

Fig. 4 Changes in the gas compounds detected from chicken meat in relation to storage interval

SAW sensors should be three times from the baseline noise. The obtained baseline noise (phase variation) is about $81 \pm$ $0.25^{\circ}$ in Fig. $5 \mathrm{~b}$, and the phase change according to chicken meat storage time was about 73 to $77 \pm 0.5^{\circ}$. From the experimental results, the difference of amplitude between two response signals is much more than 3 times.

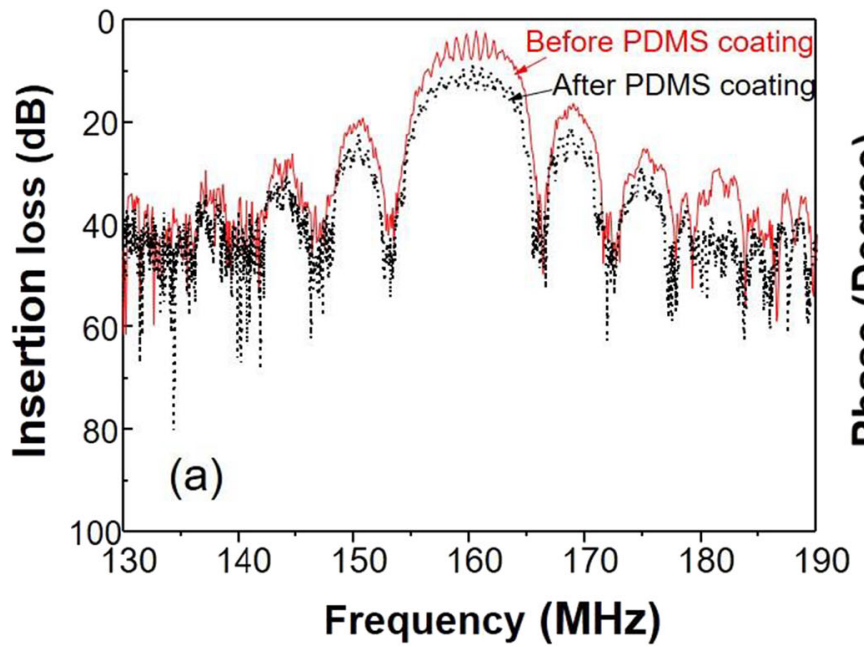

As mentioned above, the optimum thickness (quarter wavelength) of the sensitive layer is one of the most critical parameters for minimizing insertion loss (Gizeli et al. 2003) and, in this study, the ideal thickness was calculated to be about $1.69 \mu \mathrm{m}$. However, the measured thickness of the PDMS coating was about $1.8 \mu \mathrm{m}$. Because of mismatching the optimal thickness of the sensitive layer, the insertion loss was also increased. Even if the optimal thickness was not exactly achieved, the operating frequency and its bandwidth (about $60 \%$ ) could be obtained, and this will be controlled by the rotating speed (rotation per minutes) in future study.

\section{Reference Gas Sensing}

In Fig. 4, even though aldehyde gas has relatively low concentration among the other gases generated form the chicken meat, it was selected due to adverse effects on the central nervous system of human. After measuring the $\mathrm{S}_{21}$ parameter, the reference gas sensing was conducted, and its outcome is shown in Fig. 6.

Fig. 6a shows the real-time phase changes of the SAW sensor with increasing concentration of a reference gas sample. At the first $\mathrm{N}_{2}$ stabilization stage, the phase was dramatically increased and located near $-146.5^{\circ}$. This result is much different from the base line noise of the air stabilization in Fig. $5 \mathrm{~b}$. The phase shift might be strongly affected by $\mathrm{N}_{2}$ gas and other gas components in air. The measured real-time phases of the SAW sensor at about $25,50,75$, and $100 \mathrm{ppm}$ are about $146.2^{\circ},-147.5^{\circ},-148.8^{\circ}$, and $-150.4^{\circ}$, respectively. The maximum phase variation is approximately $4^{\circ}$, almost 2.5 times more than the air stabilization. While the baseline noise of the air stabilization is fixed within $1^{\circ}$, the baseline noise of the $\mathrm{N}_{2}$ stabilization changes at every concentration level from $-146.5^{\circ}$ to $-148.5^{\circ}$. The baseline noise variation is about $2^{\circ}$. The measured phases of the SAW sensor decrease as the

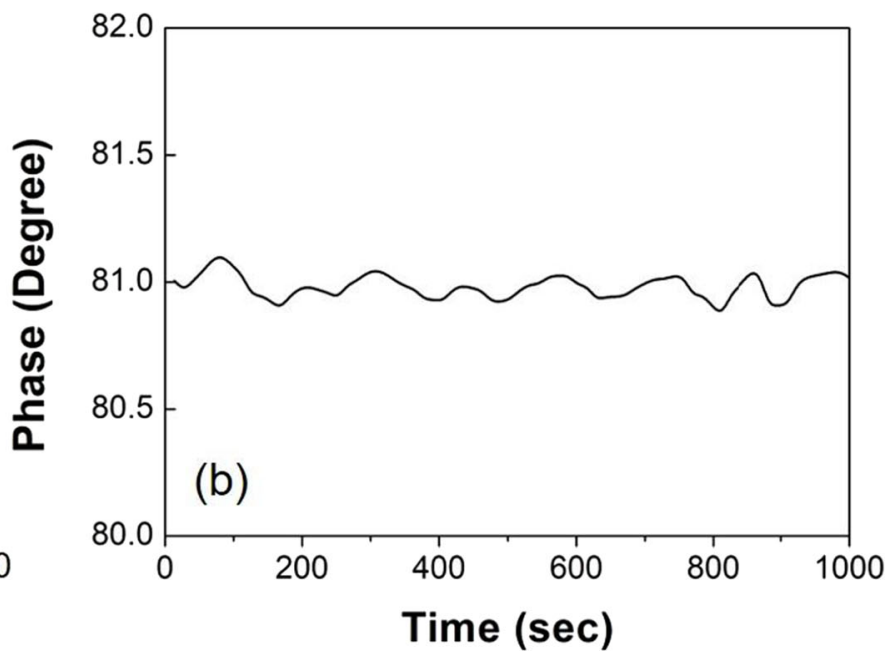

Fig. 5 Comparison of the insertion losses of the SAW sensors before and after PDMS coating: a S21 parameters before and after PDMS coating and b base line noise after PDMS coating 


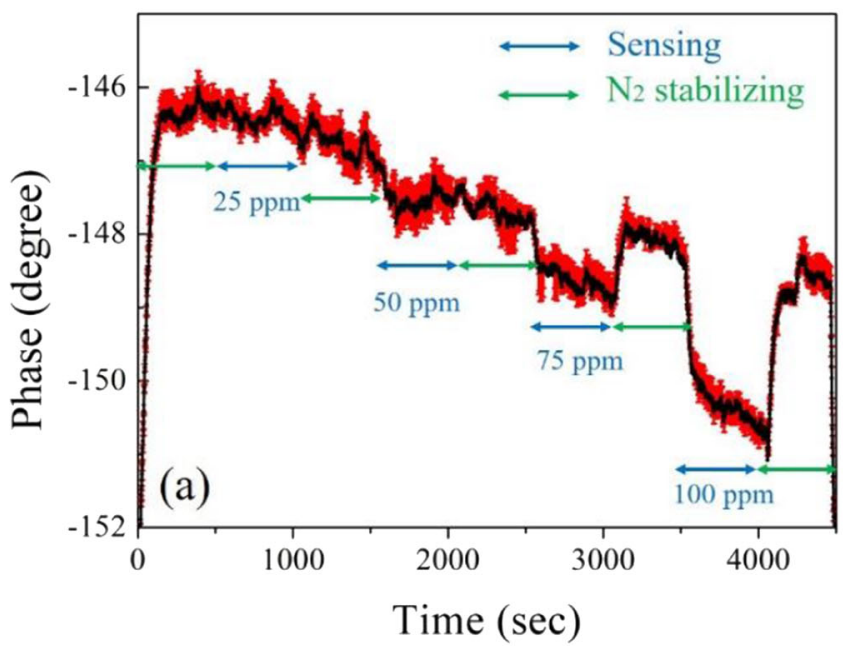

Fig. 6 Phase changes of the SAW sensor relative to reference gas with $25,50,75$, or $100 \mathrm{ppm}$ of $\mathrm{CH}_{3} \mathrm{CHO}$ : a real-time phase changes at the indicated concentrated levels (error bars in red) and $\mathbf{b}$ linear relationship

$\mathrm{CH}_{3} \mathrm{CHO}$ concentration increases. For a more precise analysis, the least squares approximation method was performed. Fig. 6b shows the linear relationship between the phase changes and the $\mathrm{CH}_{3} \mathrm{CHO}$ concentrations. The determination coefficient of the linear regression equation is about 0.98 . The measurements of $\mathrm{CH}_{3} \mathrm{CHO}$ were repeated 10 times per sample. Consequently, it can be seen that, as the concentration of $\mathrm{CH}_{3} \mathrm{CHO}$ increases by $1 \mathrm{ppm}$, the measured phase decreases by about $0.52^{\circ}$.

\section{Chicken Meat Gas Sensing}

The condition of chicken meat samples stored for 1, 5, 10, and 15 days after being slaughtered was evaluated. The number of chicken meat samples was 10 per each storage day and total

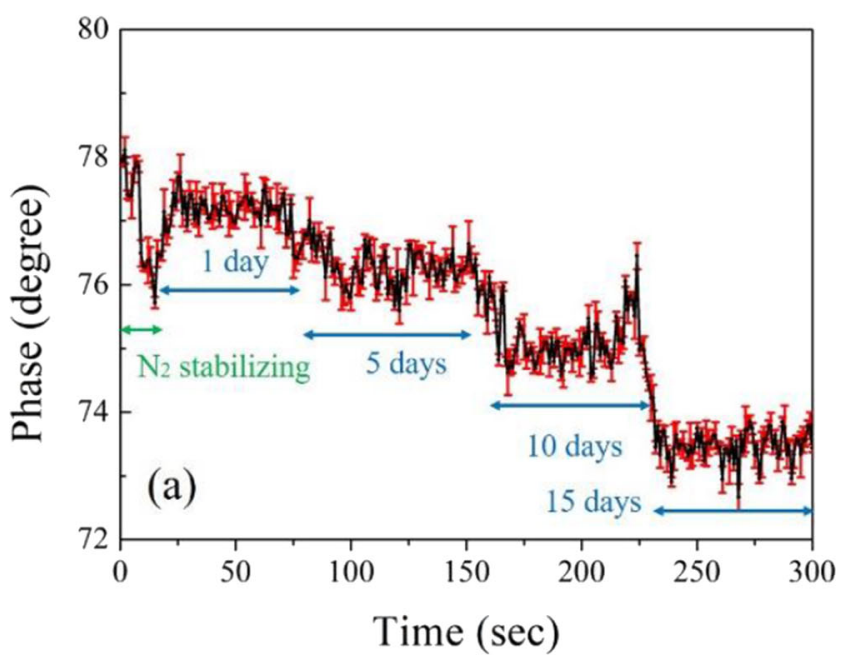

Fig. 7 Phase changes of the SAW sensor in relation to the gases detected from chicken meat samples for interval of storage in days: a real-time phase changes at the indicated storage day (error bars in red) and $\mathbf{b}$ linear

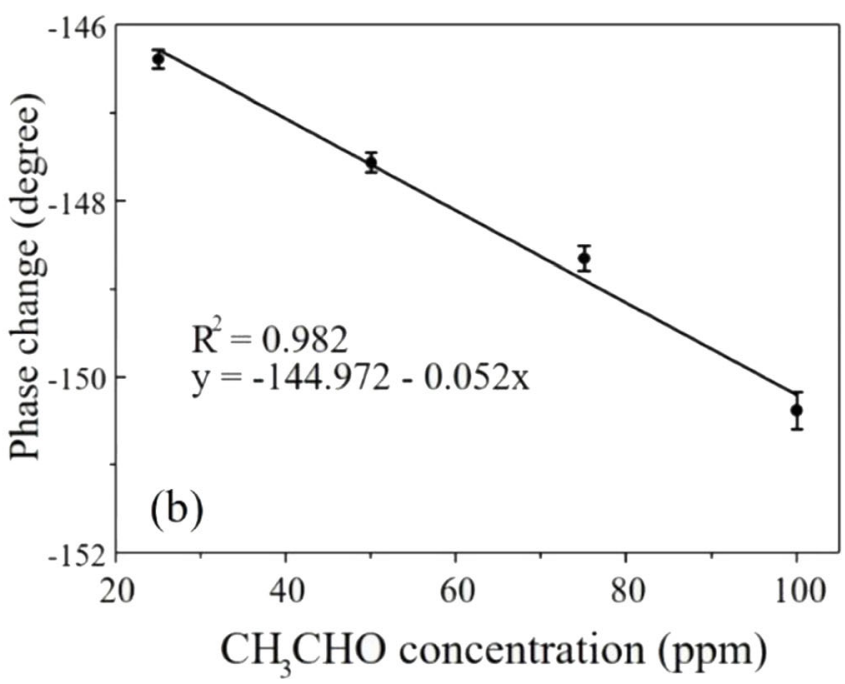

between the phase change and the $\mathrm{CH}_{3} \mathrm{CHO}$ concentration. The straight line is a data-fitted line and the standard deviation error bars represent $95 \%$ confidence intervals

40 samples were measured by 10 different SAW sensors. These data were compared with the detection results for the reference $\mathrm{CH}_{3} \mathrm{CHO}$ gas samples. To accomplish this, the experimental setup shown in Fig. 4 was used and the VOCs (including aldehyde gas) generated from chicken meat samples were measured using the SAW sensor. The measured real-time phase changes over $300 \mathrm{~s}$ of the SAW sensor in relation to the number of days the chicken meat samples had been stored. Because the collected gas from chicken meat samples was a much smaller amount than the reference gas, the sensing was conducted for about $100 \mathrm{~s}$ per each storage day. Considering the real-world environment, the stabilization of the SAW sensor was conducted in air for about $60 \mathrm{~s}$. Fig. 7 shows the results for the detection of aldehyde gas in relation to the storage time of the chicken meat samples.

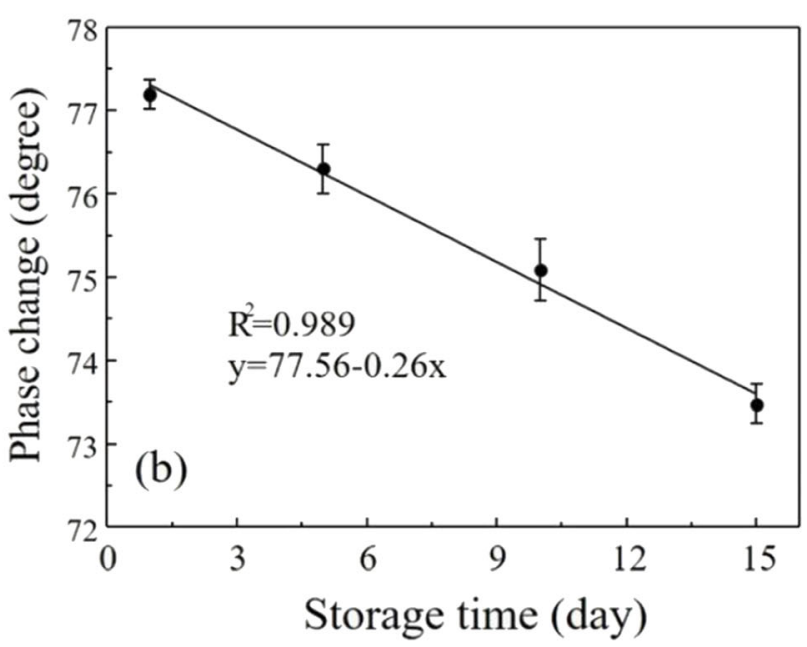

relationship between the phase change and the number of storage days. The straight line is a data-fitted line and the standard deviation error bars represent $95 \%$ confidence intervals 
In Fig. 7, the phase change is the average values of the response signals per 10 chicken meat samples, each storage day. After the stabilization, the base line noise was about $75.5^{\circ}$ and this is a very similar result with that of the base line noise experiment in Fig. 5. The measured real-time phases of the SAW sensor according to storage time are about $77^{\circ}, 76^{\circ}, 75^{\circ}$, and $73.5^{\circ}$ for $1,5,10$, and 15 days, respectively, after being slaughtered. The same linear regression analysis was conducted as in the analysis of the detection of the reference $\mathrm{CH}_{3} \mathrm{CHO}$ gas samples. Ten experiments were done per storage day. In Fig. $7 b$, a linear relationship between the phase changes and the number of storage days of the chicken meat samples is shown, and its determination coefficient was 0.989 . In addition, the measured phase of the SAW sensor decreases by $0.26^{\circ}$ every day. To obtain high sensitivity, $\mathrm{LiNbO}_{3}$ was used. From the linear regression equations of the two experiments, it was determined that $0.5 \mathrm{ppm}$ of aldehyde gas was released from the chicken meat every day. Thus, the storage time of the chicken meat samples could be evaluated quantitatively using the SAW sensor results. In addition, if we determine daycriteria for the freshness of chicken meat during its distribution, evaluating the freshness of chicken meat would be possible using the SAW sensor with the PDMS-sensitive layer fabricated in this study. This opens a promising research avenue to explore.

\section{Conclusions}

An aldehyde gas was selected as an indicator of the freshness of chicken meat due to its hazardous effects. The amounts of aldehyde gas increased rapidly after 5 days of storage, thereby indicating that the freshness of the chicken meat had decreased. A simple device for detecting aldehyde gas to evaluate the storage time of chicken meat was developed using a SAW sensing technique. A SAW device with a center frequency of $160 \mathrm{MHz}$ was fabricated on a $\mathrm{LiNbO}_{3}$ wafer. Then, PDMS polymer was coated onto a sensitive line of the SAW device as a sensitive layer for detecting aldehyde gas. To evaluate the feasibility of using the SAW sensor for freshness measurements of chicken meat, various concentrations of $\mathrm{CH}_{3} \mathrm{CHO}$ mixed with $\mathrm{N}_{2}$ gas were measured using the reactive phase changes of the newly developed SAW sensor and the measured phases decreased linearly as the $\mathrm{CH}_{3} \mathrm{CHO}$ concentrations increased. After the measurement of $\mathrm{CH}_{3} \mathrm{CHO}$ gas, aldehyde gas generated from chicken meat was measured and the phase differences could be distinguishable from those after 1 to 15 storage days. Consequently, the determination coefficient between aldehyde gas and chicken meat storage time was about 0.989 . From the experimental results, the freshness of chicken meat can thus be evaluated using the SAW sensor developed in this study.
Funding This research was supported by a development of safety measurement technology for infrastructure industry grant funded by the Korea Research Institute of Standards and Science (KRISS-2019GP2019-0014).

\section{Compliance with Ethical Standards}

Conflict of Interest The authors declare that they have no conflict of interest.

Open Access This article is licensed under a Creative Commons Attribution 4.0 International License, which permits use, sharing, adaptation, distribution and reproduction in any medium or format, as long as you give appropriate credit to the original author(s) and the source, provide a link to the Creative Commons licence, and indicate if changes were made. The images or other third party material in this article are included in the article's Creative Commons licence, unless indicated otherwise in a credit line to the material. If material is not included in the article's Creative Commons licence and your intended use is not permitted by statutory regulation or exceeds the permitted use, you will need to obtain permission directly from the copyright holder. To view a copy of this licence, visit http://creativecommons.org/licenses/by/4.0/.

\section{References}

Almenar, E., Auras, R., Wharton, P., Rubino, M., \& Harte, B. (2007). Release of acetaldehyde from $\beta$-cyclodextrins inhibits postharvest decay fungi in vitro. Journal of Agricultural and Food Chemistry, 55(17), 7205-7212. https://doi.org/10.1021/jf071603y.

Arnold, J. W., \& Senter, S. D. (1998). Use of digital aroma technology and SPME GC-MS to compare volatile compounds produced by bacteria isolated from processed poultry. Journal of the Science of Food and Agriculture, 78(3), 343-348. https://doi.org/10.1002/ (SICI)1097-0010(199811)78:3<343::AID-JSFA124>3.0.CO;2-5.

Ballantine Jr., D. S., White, R. M., Martin, S. J., Ricco, A. J., Zellers, E. T., Frye, G. C., \& Wohltjen, H. (1996). Acoustic wave sensors: theory, design and physico-chemical applications, $1 \mathrm{st}$ edn. Elsevier. https://doi.org/10.1016/B978-0-12-077460-9.X5000-X.

Bicanic, D., Persijn, S., Taylor, A., Cozijnsen, J., van Veldhuyzen, B., Lenssen, G., \& Wegh, H. (2003). Detection of ethanol and acetaldehyde released from cabbage seeds of different quality: laser photoacoustic spectroscopy versus FTIR and headspace gas chromatography. Review of Scientific Instruments, 74(1), 690-693. https://doi. org/10.1063/1.1512775.

Biswas, S., Heindselmen, K., Wohltjen, H., \& Staff, C. (2004). Differentiation of vegetable oils and determination of sunflower oil oxidation using a surface acoustic wave sensing device. Food Control, 15(1), 19-26. https://doi.org/10.1016/S0956-7135(02) 00163-9.

Boothe, D. D., \& Arnold, J. W. (2002). Electronic nose analysis of volatile compounds from poultry meat samples, fresh and after refrigerated storage. Journal of the Science of Food and Agriculture, 82(3), 315-322. https://doi.org/10.1002/jsfa.1036.

Calestani, D., Mosca, R., Zanichelli, M., Villani, M., \& Zappettini, A. (2011). Aldehyde detection by $\mathrm{ZnO}$ tetrapod-based gas sensors. Journal of Materials Chemistry, 21(39), 15532. https://doi.org/10. 1039/c1jm12561c.

Chen, F., Kong, L., Song, W., Jiang, C., Tian, S., Yu, F., Qin, L., Wang, C., \& Zhao, X. (2019). The electromechanical features of LiNbO3 crystal for potential high temperature piezoelectric applications. Journal of Materiomics, 5(1), 73-80. https://doi.org/10.1016/j. jmat.2018.10.001. 
Di Natale, C., Macagnano, A., Davide, F., D’Amico, A., Paolesse, R., Boschi, T., Faccio, M., \& Ferri, G. (1997). An electronic nose for food analysis. Sensors and Actuators B: Chemical, 44(1-3), 521526. https://doi.org/10.1016/S0925-4005(97)00175-5.

Du, M., Ahn, D., Nam, K., \& Sell, J. (2000). Influence of dietary conjugated linoleic acid on volatile profiles, color and lipid oxidation of irradiated raw chicken meat. Meat Science, 56(4), 387-395. https:// doi.org/10.1016/S0309-1740(00)00067-X.

Eilamo, M., Kinnunen, A., Latva-Kala, K., \& Ahvenainen, R. (1998). Effects of packaging and storage conditions on volatile compounds in gas-packed poultry meat*. Food Additives and Contaminants, 15(2), 217-228. https://doi.org/10.1080/02652039809374633.

Firpo, G., Angeli, E., Repetto, L., \& Valbusa, U. (2015). Permeability thickness dependence of polydimethylsiloxane (PDMS) membranes. Journal of Membrane Science, 481, 1-8. https://doi.org/10. 1016/j.memsci.2014.12.043.

Fitzgerald, J. E., Bui, E. T. H., Simon, N. M., \& Fenniri, H. (2017). Artificial nose technology: status and prospects in diagnostics. Trends in Biotechnology, 35(1), 33-42. https://doi.org/10.1016/j. tibtech.2016.08.005.

Fromme, H., Heitmann, D., Dietrich, S., Schierl, R., Körner, W., Kiranoglu, M., Zapf, A., \& Twardella, D. (2008). Raumluftqualität in Schulen - Belastung von Klassenräumen mit Kohlendioxid (CO 2 ), flüchtigen organischen Verbindungen (VOC), Aldehyden, Endotoxinen und Katzenallergenen. Das Gesundheitswesen, 70(2), 88-97. https://doi.org/10.1055/s-2008-1046775.

Giberti, A., Carotta, M. C., Fabbri, B., Gherardi, S., Guidi, V., \& Malagù, C. (2012). High-sensitivity detection of acetaldehyde. Sensors and Actuators B: Chemical, 174, 402-405. https://doi.org/10.1016/j.snb. 2012.08.016.

Gizeli, E., Bender, F., Rasmusson, A., Saha, K., Josse, F., \& Cernosek, R. (2003). Sensitivity of the acoustic waveguide biosensor to protein binding as a function of the waveguide properties. Biosensors and Bioelectronics, 18(11), 1399-1406. https://doi.org/10.1016/S09565663(03)00080-0.

Horrillo, M. C., Fernández, M. J., Fontecha, J. L., Sayago, I., García, M., Aleixandre, M., Santos, J. P., Arés, L., Gutiérrez, J., Gràcia, I., \& Cané, C. (2004). Detection of volatile organic compounds using surface acoustic wave sensors with different polymer coatings. Thin Solid Films, 467(1-2), 234-238. https://doi.org/10.1016/j.tsf. 2004.04.012.

Igene, J. O., Pearson, A. M., Merkel, R. A., \& Coleman, T. H. (1979). Effect of frozen storage time, cooking and holding temperature upon extractable lipids and TBA values of beef and chicken. Journal of Animal Science, 49(3), 701-707. https://doi.org/10.2527/jas1979. 493701x.

Jakoby, B., \& Vellekoop, M. J. (1998). Viscosity sensing using a Lovewave device. Sensors and Actuators A: Physical, 68(1-3), 275-281. https://doi.org/10.1016/S0924-4247(98)00017-X.

Joo, B., Huh, J., \& Lee, D. (2007). Fabrication of polymer SAW sensor array to classify chemical warfare agents. Sensors and Actuators B: Chemical, 121(1), 47-53. https://doi.org/10.1016/j.snb.2006.09. 013.

Jun, J.-M., Park, Y.-H., \& Lee, C.-S. (2011). Characteristics of a metalloaded SnO 2 /WO 3 thick film gas sensor for detecting acetaldehyde gas. Bulletin of the Korean Chemical Society, 32(6), 18651872. https://doi.org/10.5012/bkcs.2011.32.6.1865.

Lachenmeier, D. W., Sohnius, E.-M., Attig, R., \& López, M. G. (2006). Quantification of selected volatile constituents and anions in Mexican agave spirits (tequila, mezcal, sotol, bacanora). Journal of Agricultural and Food Chemistry, 54(11), 3911-3915. https:// doi.org/10.1021/jf060094h.

Landaud, S., Helinck, S., \& Bonnarme, P. (2008). Formation of volatile sulfur compounds and metabolism of methionine and other sulfur compounds in fermented food. Applied Microbiology and
Biotechnology, 77(6), 1191-1205. https://doi.org/10.1007/s00253007-1288-y.

Le Bihan-Duval, E., Millet, N., \& Remignon, H. (1999). Broiler meat quality: effect of selection for increased carcass quality and estimates of genetic parameters. Poultry Science, 78(6), 822-826. https://doi.org/10.1093/ps/78.6.822.

Lee, S., Kim, K.-B., \& Kim, Y.-I. (2011). Love wave SAW biosensors for detection of antigen-antibody binding and comparison with SPR biosensor. Food Science and Biotechnology, 20(5), 1413-1418. https://doi.org/10.1007/s10068-011-0194-3.

Lee, S., Kim, K.-B., \& Kim, Y. I. (2012). Mass sensitivity calculation of the protein layer using Love wave SAW biosensor. Journal of Nanoscience and Nanotechnology, 12(7), 6107-6112. https://doi. org/10.1166/jnn.2012.6381.

Lee, S., Kim, Y.-I., \& Kim, K.-B. (2013). Comparative study of binding constants from Love wave surface acoustic wave and surface plasmon resonance biosensors using kinetic analysis. Journal of Nanoscience and Nanotechnology, 13(11), 7319-7324. https://doi. org/10.1166/jnn.2013.8082.

Leonte, I. I., Sehra, G., Cole, M., Hesketh, P., \& Gardner, J. W. (2006). Taste sensors utilizing high-frequency SH-SAW devices. Sensors and Actuators B: Chemical, 118(1-2), 349-355. https://doi.org/10. 1016/j.snb.2006.04.040.

Lin, H., Ye, Q., Deng, C., \& Zhang, X. (2008). Field analysis of acetaldehyde in mainstream tobacco smoke using solid-phase microextraction and a portable gas chromatograph. Journal of Chromatography A, 1198-1199, 34-37. https://doi.org/10.1016/j. chroma.2008.05.050.

Liu, J., Wang, W., Li, S., Liu, M., \& He, S. (2011). Advances in SAW gas sensors based on the condensate-adsorption effect. Sensors, 11(12), 11871-11884. https://doi.org/10.3390/s111211871.

Lopez-Ferrer, S., Baucells, M. D., Barroeta, A. C., \& Grashorn, M. A. (2001). N-3 enrichment of chicken meat. 1. Use of very long-chain fatty acids in chicken diets and their influence on meat quality: fish oil. Poultry Science, 80(6), 741-752. https://doi.org/10.1093/ps/80. 6.741 .

Loutfi, A., Coradeschi, S., Mani, G. K., Shankar, P., \& Rayappan, J. B. B. (2015). Electronic noses for food quality: a review. Journal of Food Engineering, 144, 103-111. https://doi.org/10.1016/j.jfoodeng. 2014.07.019.

McHale, G., Newton, M. I., \& Martin, F. (2002). Theoretical mass sensitivity of Love wave and layer guided acoustic plate mode sensors. Journal of Applied Physics, 91(12), 9701. https://doi.org/10.1063/1. 1477603.

Mitsubayashi, K., Matsunaga, H., Nishio, G., Toda, S., \& Nakanishi, Y. (2005). Bioelectronic sniffers for ethanol and acetaldehyde in breath air after drinking. Biosensors and Bioelectronics, 20(8), 1573-1579. https://doi.org/10.1016/j.bios.2004.08.007.

Nanto, H., Yokoi, Y., Mukai, T., Fujioka, J., Kusano, E., Kinbara, A., \& Douguchi, Y. (2000). Novel gas sensor using polymer-film-coated quartz resonator for environmental monitoring. Materials Science and Engineering: C, 12(1-2), 43-48. https://doi.org/10.1016/ S0928-4931(00)00156-9.

Newman, J. C., \& Verdin, E. (2014). Ketone bodies as signaling metabolites. Trends in Endocrinology \& Metabolism, 25(1), 42-52. https://doi.org/10.1016/j.tem.2013.09.002.

Ning, X., Yang, J., Zhao, C. L., \& Chan, C. C. (2016). PDMS-coated fiber volatile organic compounds sensors. Applied Optics, 55(13), 3543-3548. https://doi.org/10.1364/AO.55.003543.

Olafsdottir, G., Jonsdottir, R., Lauzon, H. L., Luten, J., \& Kristbergsson, K. (2005). Characterization of volatile compounds in chilled cod (Gadus morhua) fillets by gas chromatography and detection of quality indicators by an electronic nose. Journal of Agricultural and Food Chemistry, 53(26), 10140-10147. https://doi.org/10. $1021 / \mathrm{j} f 0517804$. 
Pan, Y., Yang, L., Mu, N., Shao, S., Wang, W., Xie, X., \& He, S. (2014). A SAW-based chemical sensor for detecting sulfur-containing organophosphorus compounds using a two-step self-assembly and molecular imprinting technology. Sensors (Switzerland), 14(5), 8810-8820. https://doi.org/10.3390/s140508810.

Patsias, A., Badeka, A. V., Savvaidis, I. N., \& Kontominas, M. G. (2008). Combined effect of freeze chilling and MAP on quality parameters of raw chicken fillets. Food Microbiology, 25(4), 575-581. https:// doi.org/10.1016/j.fm.2008.02.008,

Saha, K., Bender, F., Rasmusson, A., \& Gizeli, E. (2003). Probing the viscoelasticity and mass of a surface-bound protein layer with an acoustic waveguide device. Langmuir, 19(4), 1304-1311. https:// doi.org/10.1021/la026806p.

Shen, C.-Y., \& Liou, S.-Y. (2008). Surface acoustic wave gas monitor for ppm ammonia detection. Sensors and Actuators B: Chemical, 131(2), 673-679. https://doi.org/10.1016/j.snb.2007.12.061.

Silva, C. M., \& Glória, M. B. A. (2002). Bioactive amines in chicken breast and thigh after slaughter and during storage at $4 \pm 1{ }^{\circ} \mathrm{C}$ and in chicken-based meat products. Food Chemistry, 78(2), 241-248. https://doi.org/10.1016/S0308-8146(01)00404-6.

Soncin, S., Chiesa, L. M., Cantoni, C., \& Biondi, P. A. (2007). Preliminary study of the volatile fraction in the raw meat of pork, duck and goose. Journal of Food Composition and Analysis, 20(5), 436-439. https://doi.org/10.1016/j.jfca.2006.09.001.

Soyer, A., Özalp, B., Dalmış, Ü., \& Bilgin, V. (2010). Effects of freezing temperature and duration of frozen storage on lipid and protein oxidation in chicken meat. Food Chemistry, 120(4), 1025-1030. https://doi.org/10.1016/j.foodchem.2009.11.042.

Staginus, J., Aerts, I. M., Chang, Z., Meijer, G. C. M., de Smet, L. C. P. M., \& Sudhölter, E. J. R. (2013). Capacitive response of PDMScoated IDE platforms directly exposed to aqueous solutions containing volatile organic compounds. Sensors and Actuators B: Chemical, 184, 130-142. https://doi.org/10.1016/j.snb.2013.04. 041.

Torino, S., Conte, L., Iodice, M., Coppola, G., \& Prien, R. D. (2017). PDMS membranes as sensing element in optical sensors for gas detection in water. Sensing and Bio-Sensing Research, 16, 74-78. https://doi.org/10.1016/j.sbsr.2017.11.008.

Wen, W., Shitang, H., Shunzhou, L., Minghua, L., \& Yong, P. (2007). Enhanced sensitivity of SAW gas sensor coated molecularly imprinted polymer incorporating high frequency stability oscillator. Sensors and Actuators B: Chemical, 125(2), 422-427. https://doi. org/10.1016/j.snb.2007.02.037.

Weng, X., Chon, C. H., Jiang, H., \& Li, D. (2009). Rapid detection of formaldehyde concentration in food on a polydimethylsiloxane (PDMS) microfluidic chip. Food Chemistry, 114(3), 1079-1082. https://doi.org/10.1016/j.foodchem.2008.10.027.

Wyszynski, B., Sekine, M., Nakamoto, T., Nakaso, N., \& Noguchi, K. (2010). Spherical SAW devices with self-assembled lipopolymers for odor-sensing. Sensors and Actuators B: Chemical, 144(1), 247254. https://doi.org/10.1016/j.snb.2009.10.059.

Yamashita, K., Noguchi, M., Mizukoshi, A., \& Yanagisawa, Y. (2010). Acetaldehyde removal from indoor air through chemical absorption using L-cysteine. International Journal of Environmental Research and Public Health, 7(9), 3489-3498. https://doi.org/10.3390/ ijerph7093489.

You, J., Yan, T., Zhao, H., Sun, Z., Xia, L., Suo, Y., \& Li, Y. (2009). A sensitive fluorescence reagent for the determination of aldehydes from alcoholic beverage using high-performance liquid chromatography with fluorescence detection and mass spectrometric identification. Analytica Chimica Acta, 636(1), 95-104. https://doi.org/10. 1016/j.aca.2009.01.036. 